\title{
The Collaborative Propagation Mechanism of Traditional Science Media and New Science Media
}

\author{
Shengyue Hao ${ }^{1}$ Jiajia Jin $^{2}$ \\ ${ }^{1,2}$ Beijingjiaotong University, Beijing, China \\ 13120653@bjtu.edu.cn
}

\begin{abstract}
Establishment of collaborative propagation mechanism between traditional science media and new science media has positive effect on the promoting of China's science and technology propagation. This paper first analyzes the possibilities for traditional and new science media to integrate in terms of organization, contents and channels, providing a start point for the establishment of collaborative propagation mechanism. Subsequently, the author emphasizes on the propagation mode, organizational system and management structure for traditional media and new media to propagate collaboratively. The author also proposes several specific practices in the collaborative propagation mechanism of traditional media and new media as suggestions for relevant departments and science workers.
\end{abstract}

Keywords: Science Media, Collaborative Propagation, Mechanism

\section{Introduction}

The rapid development of information technology is leading people to step into an information era in which the consumer demand is unprecedented, therefore any isolated media is unable to meet audiences' growing internal demand independently. The propagation forms of science media is changing. In order to push the propagation of science and technology into a higher position, traditional media and new media must make up each other. Through the integrations in terms of organization structure, communication contents etc., a social network-based collaborative propagation mechanism targeting individual demand of audiences, using a variety of media and terminals synthetically, with text, pictures, sound, video and other interactive elements demonstrating technological information to achieve the best propagation effect can be built.

Foundation Item:National Soft Science Major Project(2013GXS5B179)

\section{The Feasibility of Collaborative Propagation Mechanism of Traditional and New Science Media}

Traditional media is rigorous, authoritative, but there are inevitable drawbacks such as poor immediacy and interaction. Representing by the Internet, New media has high propagating efficiency and speed so that the openness of science propagation has been improved greatly. However, it also brings problems like exaggerating and distorting technology facts, dislocating public opinion, etc. The advance of science propagation can be supported by the use of the advantages of traditional and new science media. A staring point is provided by the possibilities of integration in the organizational structure, propagation content and channel between traditional media and new media.

\subsection{The Organizational Integration of Different Media.}

The organizational structure of traditional media has shown a clear trend of integration at the beginning of this century. The appearance and development of Newspaper Group, Media \& Entertainment Group and Publishing Group lead to a more rational distribution of media resources and improve the industrial concentration. Recently, with the development of science and technology, media organizations accelerate the pace of integration, a series of merges and restructuring behaviors blur the boundaries among those three traditional media. At the same time, the appearance of new media broadens the developing vision of traditional media and pushes them into a multimedia group. In March 2002, Beijing "Qianlong" integrated traditional local media resources to set up a large network media platform. The "Eastday" which is founded by nine joint ventures in Shanghai and the "South.cn" which integrates the resource of domestic well-known newspaper media such as Nanfang Media, Yangcheng Newspaper, Guangzhou Daily and TV media such as Guangdong Television and Nanfang Television are all successful cases in organizational integration. Diversification of various media forms strengthens the links and complementarities among them, which is conducive to the perfection of product structure and industrial structure as well as the 
enhancement of the media group's overall competitiveness. Meanwhile, resources reallocating provided by designing and controlling diverse media products can definitely make contribute on the integration of content for traditional media and new media $^{1}$.

\subsection{The Content Integration of Different Media.}

New science media and traditional science media have a large commonality in the selecting of content they disseminate. Much of the content of new media is a report of traditional media, with the help of new media technologies such as network link, visual images, audio, video; the new media content is more appealing and attractive. Take electronic newspaper for example, it combines new media's feature with printed newspaper to make an online version of printed newspaper. In content, online version can explore background information deeply and publish a detailed report with the content printed newspapers provide. It can also take the advantages of multimedia technology to provide vivid sound and image services. Meanwhile, numerous of news with a high spreading speed provides traditional media rich source of information. The traditional media chooses events which attract audiences the most and influences public the most to report so that the strength of its credibility and authority as well as its expertise and extensive experience in reporting can be used to enhance the effect of technology propagation, to achieve the content integration of traditional and new media.

\subsection{The Channel Integration of Different Media}

The channel integration of traditional media and new media is supported by technology development. With the advancement of satellite technology, digital technology and network technology, as well as their applying in broadcasting and communication, new media provides audiences a science communication platform with more involvement and more convenience. At the same time, traditional media can also make use of these platforms in supporting new technologies. Nowadays, most of domestic influential newspapers, radio and television stations have established their own websites. Domestic science and education channels, such as CCTV and Beijing, Tianjin, Shanxi, Chongqing, Guangxi science Channel and other local television stations have produced multitudes of network products and registered on Sina Weibo to reinforce the interaction with audiences. With the propagation channels provided by new media, traditional media can publish scientific knowledge, organize science activities, therefore create strong scientific atmosphere. It can be seen that technologies which support the development of new media are providing a steady stream of energy for science propagation. At the same time, the great potential creativity of traditional media has gradually shown us that they are trying to make full use of all kinds of new propagation channels to make progress. The boundary between traditional and new media is disappearing gradually.

Media Convergence has become the mainstream and key performance of the development trend of media, the integration of organization, content and channels between traditional media and new media shows us the possibility of their collaborative propagation in the future. Traditional media and new media are combining and developing together mutually. Relying on the rapid development of information technology and the collapsing of the barriers between different forms of media, the collaborative propagation is just around the corner.

\section{The Collaborative Propagation Mechanism of Traditional and New Science Media}

The 8th Chinese citizen science literacy survey result shows that in 2010, the top three media channel citizens choose to obtain scientific development information are television $(87.5 \%)$, newspapers $(59.1 \%)$ and network $(26.6 \%)$. According to the survey, it can be inferred that the collaborative propagation of traditional and new science media may play a significant role in promoting science. It is a general trend to set up a collaborative mechanism for traditional and new media to champion our science propagation task. To create this mechanism, we shall prepare from the aspects of propagation modes, organizational system, and management structure.

\subsection{Social Network-Based Collaborative Propagation Mode of Traditional and New Science Media}

As an important new media form, social network has become an important platform for traditional media to obtain and publish information. Traditional media can make use of new media to achieve the expansion of advertising, customer service, exploring potential market; while new media can take the advantage of traditional media's authority and credibility to ensure the quality of its product. Future trends in science and technology propagation should take social networks (Weibo, etc.) as the basis for the Internet platform to penetrate into the search engine, e-commerce, online games, e-mail, instant messaging, and many other areas. Social networks become a tie linking traditional media and new media get together to promote the development of science propagation.

Recently, China's major news events almost all experienced a "trilogy" which was originated on the network and then traditional media followed up to report, finally solved the problem along with the network. Traditional media verifies and digs further of the truth of network information, eventually makes effort on solving the problem with Internet to achieve social fairness and justice. Applying this positive interaction of 
news report between traditional media and the Internet to the field of science propagation can offer great help on the collaborative mode of traditional media and new science media studies. The Wenchuan earthquake report happened in 2008 is a successful case to cope with public disasters report, its "open" report mode is not only a useful attempt of traditional media and new media's collaborative propagation in news area, but also enlightens our minds of how to achieve the collaborative propagation in science area.

The openness of news and information source is the key element in keeping the earthquake report seasonable. Internet which developed interactively in Web2.0 era turns everyone into an information source. People who experienced the disaster record the live picture of earthquakes with their cell phones and post it on Weibo with several words, pictures even videos. Internet users pay massive attention and they repost the Weibo so that significant amounts of news and information can be seen and known in a larger scale. Meanwhile, as the most authoritative administrative of earthquake information, the government timely publish information in forms of official gazette, press conferences through the press, radio, television and other media so that government instructions and rescue measures can be conveyed to the public. Almost immediately, major news media keeps following up on the latest disaster scene. Science media takes actions as well. They produce varieties of science product whose topic is relevant to the earthquake, such as "How is earthquake generated", "How to save yourself in an earthquake" etc. These science products are propagated through both traditional media and new media. A strong connection between propagation content and hot public concerned issues is established which substantially promulgate the scientific and technological propagation effect.

Earthquake report of Wenchuan breaks the traditional "single channel" propagation mode and opens up a joint propagation mode in which a variety of media report work together, regardless of their different levels, areas and types. It is a good example of the fact that the traditional media and new media propagate collaboratively to enhance the effect of science propagation. Figure 1 shows the Social Network-Based Collaborative Propagation Mode of Traditional and New Science Media.

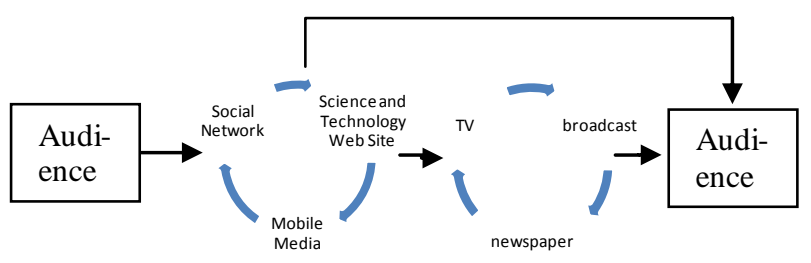

Figure 1 Social Network-Based Collaborative Propagation Mode of Traditional and New Science Media.

With the advantage of numerous network users, fast propagation speed and flattening propagation mode, social network plays a role of information hub. Anyone who has an online cell phone can post his news in a form of short messages, along with pictures, sounds and so on. Once a new message is posted online, it will quickly attract more users to make comments and repost the message, expanding the propagation scope of the message. Subsequently, these messages are propagated through other forms of communication, such as websites, mobile phones and so on. Finally they become hot topics and arise widespread concern in the community.

To take full advantage of the information platform built by new media, traditional media needs to transform from the traditional "Interior content cognition" to "Internet-based content cognition", pays attention to varies kinds of widespread hot events on the Internet, emphasizes on the sudden occurrence of disasters and false information originated from Internet, releases the correct and scientific information timely, produces popular science products to promulgate scientific and technological propagation. Under the condition of lacking important events which can provide an entry point for science media, traditional media should continue to focus on and track the network, make use of the giant information platform provided by new media to classify and optimize their content, so that a steady stream of creative inspiration can be found to produce science products.

The main point of the above collaborative mode of science propagation is to change traditional media's mind from "content first, then network" to "network first then content", that's to say, provide users with personalized information in accordance with the requirement of the Internet. The core idea is to combine the Internet media platform trends with traditional media content advantages. New media is a hatchery, collecting station and broadcasting station of a wide range of science information. Traditional media then chooses useful science information to process them into authoritative and reliable science products. Finally, with the power of new media, these science products can be preserved on the Internet and known by more people.

\subsection{The Media Linkage of Organizational System Inside Media Group}

The current multi-media convergence is a spontaneous behavior driven by the development of technology and market. Although there are some Media Groups, the actual operation of traditional media and new media is still set apart. To display the advantages of media group and promote further development of traditional media and new media, media convergence should be a process of chemical integration rather than administratively kneading which requires the formation of different forms of media group, and the establishment of an organizational system, which can fully mobilize those media groups ${ }^{2}$. 
Media linkage refers to a linkage mechanism created in different forms of media according to the positioning of the different forms of media within the Media Group. Several "linkage groups" are founded to achieve media linkage. For instance, certain radio, television, websites focus on life science can be classified into a linkage group as well as others can form another technological science linkage group of different themes. Such structure will not only allow the media of the same information to express them differently based on their own characteristics and avoid the homogenization in media content, but also strengthen the interaction among different forms of media so that collaborative propagation of traditional media and new media can be promoted.

To ensure the effect of media linkage, the media group should establish a hierarchical organizational system with top level, intermediate level and executive level. The top level is responsible for major strategic issues, such as make decisions on the composition and work area of different "linkage groups". The intermediate level mainly focuses on planning and organizing important activities and so on. Giving full play to the spread advantage of each media forms to achieve differential expression, enhance result of dissemination; executive departments focusing on plan tactical level activities, pay attention to work and innovation. The organizational system, which regards linkage of media as the core, ensures different forms of media to combine together according to the Media Group's need at any time. It also fully encourages every media to reinforce their strengths, highlighting differential advantages.

\subsection{The Management Structure of Traditional and New Science Media's collaborative propagation}

Although the trend of media convergence among the three traditional media, between traditional media and new media has emerged for quite a while, the previous pattern that national policies limit the interpenetration of radio, television, newspapers and telecommunications has not been broken. Separate management of various departments hinders the collaborative propagation of traditional and new science media greatly. Usually, a new media as a result of convergence of many different media forms is regulated by several separate departments. For instance, network-television is regulated by telecommunications, broadcasting and the Ministry of Culture dues to the involvement of telecommunications network, radio and television. Without unified coordination mechanism, the regulatory is confusing and inefficient.

To solve the problem occurred in media convergence process, government should broad the limit of traditional media ownership and break the boundaries between media types. The government should also encourage and promote cooperation of various sectors, accelerate the integration of functions of the Press and Publication Administration and the Ministry of Information Industry, establish a unified management agency to control the cross-media collaboration and scale, lead and coordinate collaborative propagation of traditional media and new media, regulate the media market under the new situation.

\section{Summary}

Media convergence is an inevitably development trend of media industry in the future, both traditional media and new media should grasp this opportunity to seek development and collaborative propagation to achieve complementary advantage. To establish collaborative propagation mechanism of traditional science media and new science media, we must first improve the communication environment of traditional media and new media, which can be achieved by optimizing organized media group system and completing the management structure of different media forms. The core of traditional media and new science collaborative science media communication mechanisms is to build social network-based collaborative mode of propagation, viewing social network as the connection of traditional media and new media to make sure traditional media and new media's strengths can be made full use and the all-round and three-dimensional technology propagation effect can be achieved.

\section{References}

[1]Qing Deng, Jing Niu. Media convergence in the context of the reform and development of the media industry [J]. Journalism Lover, 2010, 1: 020.

[2]Lei $\mathrm{Bi}$. The Chinese media convergence path selection-Chengdu Media Group Media Convergence practice[J]. Media, 2010 (010): 14-17. 